\title{
Improving nurses' knowledge and skills regarding tocolytics for inhibiting preterm labor
}

\author{
Hanan Elzeblawy Hassan*1, Elsayda Hamdy Nasr ${ }^{2}$ \\ ${ }^{1}$ Maternal \& Newborn Health Nursing, Faculty of Nursing, Beni-Suef University, Egypt \\ ${ }^{2}$ Maternity, Obstetric \& Gynecological Nursing, Faculty of Nursing, Port said University, Egypt
}

Received: November 28, 2016

DOI: $10.5430 / \mathrm{cns} . v 5 \mathrm{n} 1 \mathrm{p} 1$
Accepted: December 11, $2016 \quad$ Online Published: December 16, 2016

URL: http://dx.doi.org/10.5430/cns.v5n1p1

\begin{abstract}
Background: Approximately $10 \%$ of all pregnant women who experience an episode of threatened preterm labor requiring hospital admission and Tocolytic therapy may be considered for them. Nursing care is the main critical component of this therapy. Nurses' Knowledge deficit and poor practical skills regarding tocolytics and its administration, care, surely, will interfere with their ability to achieve consistent and positive patient care outcomes.

Aim: The aim is to assess the impact of an instructional program on knowledge and practices of maternity nurses regarding pregnant women with tocolytics administration for inhibiting preterm labor.

Methods: A quasi-experimental design was used with all nurses $(n=30)$ working in the inpatient of obstetrics and gynecology department in all general hospitals in Port Said city. Tools: Three tools were used; structured interview questionnaire, pre/post-test knowledge assessment sheet and an observation checklist.

Results: The mean age of the participant nurses is $30.6 \pm 10.3$. The majority (86.6\%) of them had nursing secondary school. All nurses archived better scoring in both knowledge and skills after implementing the program than before it. A significant difference between pre and post-test was observed $(p<.01)$.

Conclusions: There is a progression of satisfactory score and regression of unsatisfactory one. The knowledge and practical scoring in the post-test are better than pre-test. This is mirrored the effect of the program.

Recommendations: Continuing educational programs should be developed to teach and train nurses about the care of preterm, a complete assessment of maternal history, accurate examination of preterm labor and knowledge of tocolytics drugs.
\end{abstract}

Key Words: Preterm labor, Tocolytics, Educational program

\section{INTRODUCTION}

Preterm birth (PTB) is commonly defined as birth prior to 37 weeks of gestation. ${ }^{[1,2]}$ It is characterized by uterine contractions occurring at least every 10 minutes and lasting at least 30 seconds, which result in premature cervical effacement and/or dilation. ${ }^{[3]}$

The incidence of PTB continues to rise worldwide. ${ }^{[4]}$ An estimated fifteen million babies are born preterm and this number is rising annually. Across 184 countries, the PTB ranges from $5 \%$ to $18 \%$ of babies born. ${ }^{[1]}$ It affects $5 \%$ to $12 \%$ of pregnant women in the developed world. ${ }^{[5]}$ Sevenpoint-five percent of newborns were born preterm in Australia in 2011. ${ }^{[6]}$ Moreover, in Queensland in 2011, PTB accounted for $7 \%$ of singleton births, $60 \%$ of multiple births, around $13 \%$ of the births to Aboriginal and/or Torres Strait Islander women and $82 \%$ of the 610 perinatal deaths. ${ }^{[7]}$ In Ireland, the incidence of PTB is $4.4 \%$, compared with $12 \%$

\footnotetext{
*Correspondence: Hanan Elzeblawy Hassan; Email: nona_nano_1712@yahoo.com; Address: Maternal \& Newborn Health Nursing, Faculty of Nursing, Beni-Suef University, Egypt.
} 
in the United States. ${ }^{[8]}$

Additionally, PTB is considered the second largest direct cause of child mortality in children younger than five years, responsible for $75 \%$ of neonatal mortality, $70 \%$ of short \& long-term neonatal morbidity as well as $50 \%$ of the term neurological impairments in children. PTB account for onethird of all health care spending on infants and one-tenth of spending for children. ${ }^{[2,9,10]}$

Premature infants born after 32 weeks of gestation tend to have less chance of problems than those born earlier; for infants born before 24 weeks of gestation, the possibilities of survival are very slim. Many that do survive could have long-term health problems as cerebral palsy, which can last a lifetime. They may also have other problems, such as learning disabilities (appear later in childhood or even in adulthood), trouble with talking as well as with moving their body (poor motor skills). ${ }^{[1,11]}$

Tocolytics agents have not proven to be efficacious in preventing PTB or reducing neonatal morbidity or mortality, today, the first purpose of tocolytic therapy is to delay delivery for 48 hours ( 2 days) to allow the maximum benefit of Glucocorticoids to decrease the incidence of respiratory distress syndrome (RDS). While tocolytics may be successful for 48 hours once membranes are intact, other clinical studies suggest that the effectiveness of tocolytics is only slightly better than bed rest $\&$ hydration, both of which have fewer adverse effects than tocolytic therapy. ${ }^{[12-15]}$

Tocolytics (also called anti-contraction medications or labor represents) are medications used to inhibit uterine contractions and suppress premature labor (from the Greek tokos, childbirth, and lytic, capable of dissolving). Tocolytics agents include nifedipine, terbutaline, and magnesium sulfate. Oral or parenteral tocolytic drugs may prolong gestation for two to seven days, which can buy time for the administration of betamethasone, a glucocorticoid drug which greatly accelerates fetal lung maturity. ${ }^{[8,16]}$

Approximately ten percent of all pregnant women who experience an episode of threatened preterm labor requiring hospital admission. ${ }^{[2]}$ The role of nurses for preterm labor is very important to monitor maternal and fetal condition when using tocolytic to identify the adverse effect. Close monitoring in an inpatient setting is indicated for fetal \& maternal safety, uterine contractions, intake \& output are monitored. In addition, the lungs should be auscultated every 4 hours to 8 hours for evidence of pulmonary edema. Careful record keeping cervical dilatation \& effacement. Careful surveillance of the fetus is also required, and generally includes continuous fetal heart rate monitoring. In addition, antenatal corticosteroids are administered if the patient is at risk of delivering between 24- and 34-week gestation, and immediately stop the medication if fetal distress noted and start primary IV solution. ${ }^{[3,16]}$

\subsection{Significance of the study}

PTB is among the most challenging obstetric complications encountered by the obstetricians and pediatricians. In the United States, preterm delivery affects approximately one in ten births and is the cause of at least $75 \%$ of neonatal deaths. Morbidity can be reduced with the early and accurate diagnosis of preterm labor, intervention to delay preterm delivery.

The use of more selective tocolytic therapy and antenatal corticosteroids offer hope that new therapeutic approaches which increase rates of fetal survival and improve neonatal outcome. ${ }^{[2,17]}$ The nurses are comprising the greatest group of health care providers. ${ }^{[18]}$ Many composed reports have tended to the effect of nursing on health care outcomes and those reports propose that positive patient outcomes depend on a greater extent on the skills of nurses than on the available technology. Numerous researchers, analysts, investigators, agents, supervisors, and managers have endeavored attempted, hence, to define nursing's effect on and contribution to care. ${ }^{[19,20]}$

In Egypt, the vast majority of the preterm labor studies emphasized on medical intervention, thus, little is thought about the nursing role. As nurses are the ones who responsible for administration and follow up selective tocolytic therapy to pregnant women in preterm labor as well as the quality of care provided to the patients, their perspectives on the effectiveness of their care are very important, thus, the present study is very important as it was directed to develop an educational program of nursing care toward preterm labor.

\subsection{Aim of the Study}

The aim of the current study is to implement an educational program for maternity nurses for improving their knowledge and technical skills towards tocolytics administration for inhibiting preterm labor.

\subsection{Research hypothesis}

Nurses' knowledge and practices will be progressed after implementing the program.

\section{Methodology}

\subsection{Technical design}

The technical design of the study included the following: research design, the setting of the study, sampling, and tools for data collection. 


\subsubsection{Study design}

A quasi-experimental design (pre-test and post-test) was used to examine the impact of an educational program on nurses' knowledge and nursing management of preterm labor patients receiving tocolytics.

\subsubsection{Setting}

Data were collected in inpatient obstetrics and gynecology department in the following hospitals (all public hospitals) in Port Said city as they provide a wide range of maternity services:

(1) El-Tadamon Hospital.

(2) Port Said General Hospital (El-Amery).

(3) Port Fouad General Hospital.

\subsubsection{Subjects}

All staff nurses $(\mathrm{n}=30)$ working in the inpatient of obstetrics and gynecology department in the previously mentioned hospitals in Port Said city, which were targeted for assessment of their knowledge and practice.

Inclusion criteria. Subjects were included as:

(1) Working in inpatient of obstetrics and gynecology department.

(2) With the experience at least one year.

(3) The workload for each nurse was 8 hours.

\subsubsection{Tools for the study}

Tools for data collection were 3 tools:

Tool (I): A structured interviewing questionnaire for Nurses:

After a comprehensive reviewing the related literature, the researchers designed interviewing questionnaire sheet for the nurses. It encompassed socio-demographic and personal characteristics such as age, years of experience, place of work and educational level.

\section{Tool (II): Pre/post-test knowledge assessment sheet:}

This tool was designed by the researchers and consisted of two major parts: The first part was designed to assess the knowledge of the nurse regarding preterm labor such as (definition of preterm labor, causes, complication for mother and fetus).

The second part was designed to assess the knowledge of the nurse regarding tocolytics drugs such as (definition of tocolytic drugs, types, uses, side effects of tocolytic on the mother and her fetus) and the nursing care for women during tocolytics administration.

The Scoring system:

Published by Sciedu Press
By scoring the items of knowledge to assess the promotion of knowledge:

- A score equal 1 was given for each correct answer, and 0 for either unknown or incorrect ones. Summing the scores of all items to get a total score for each section. (1) Maximum points of the nurses' knowledge regarding PTB were equaled 14;

(2) Maximum points for nurses' knowledge regarding the tocolytics drug were:

(i) Equal 4 for general knowledge about tocolytics drug.

(ii) Equal 4 for knowledge about the most effective types of tocolytics drugs.

- Total scoring of the nurses' knowledge regarding preterm labor and tocolytics drug was equal 22.

(1) Satisfactory: 60\%-100\%, score 13-22;

(2) Unsatisfactory: 0\%-59\%, score 0-12.

\section{Tool (III): Observation checklist:}

Observation checklist was designed to collect data about to the nurses' performance and the nursing care for women with preterm labor during tocolytics drugs administration. It encompassed two main parts:

- Part one included physical assessment such as:

(1) Assess deep tendon reflexes every 12 hours.

(2) Assess for signs of pulmonary edema every 12 hours.

(3) Assess daily weights.

(4) Measure the intake and output every 24 hours.

(5) Assess the uterine contraction every 2 hours, which included frequency and strength.

(6) Assess fetal heart sound (FHS).

(7) Assess the temperature every 4 hours.

(8) Assess the blood pressure (BP) every 4 hours.

(9) Assess the plus every 4 hours.

- Part two, which included:

(1) Health teaching regarding breathing exercise.

(2) Assess the time of bed rest and continued observation therapeutic sleep for the women.

The Scoring system:

By scoring the items of practices to assess the promotion of practices:

- A score equal 1 was given for each done step, a score equal 0 was given if the step wasn't done. The total score for each section had been got by summing of the scores of all items. The maximum score was equal 11 for nurses' performance and the nursing care during tocolytic drug administration for women with preterm labor. 
- Scoring key for the nurses' practices regarding tocolytics drug:

(i) Satisfactory: if scores more than 60\%, score 7-11;

(ii) Unsatisfactory: if less than 60\%, score 0-6.

\subsection{Operational design}

\subsubsection{Testing the validity and reliability of the tools}

Testing the Validity: An opinionnaire sheet was designed to test the validity of the tools. A jury, including five professors of woman health, maternity, obstetrics \& gynecologic nursing, and community \& family health nursing to ascertain their content validity. Tools were modified according to the jury's results and judgment.

Testing the Reliability: Cronbach's Alpha coefficient test was used to confirm the stability of the questionnaire. It has been shown that it equals to 0.0629 is an excellent factor in such studies.

\subsubsection{Pilot study}

The pilot study was carried out on three nurses $(10 \%$ of the study sample) to test for the clarity, relevance, and applicability of the study tools. Nurses involved in the pilot were excluded from the study in order to avoid contamination of the study sample. The necessarily required modifications were done.

\subsubsection{Phases of field work}

The researcher collected data from the previously mentioned hospitals twice per week, according to the time available to the nurses and their shift. Each nurse took approximately 60-90 minutes to complete the questionnaire and observed for clinical practices regarding the care of women with preterm labor during tocolytic administration. The four following mentioned phases were adopted to fulfill the purpose of the current study: (1) assessment phase, (2) planning phase, (3) implementing phase, (4) evaluation phase. These phases were carried out from the beginning April 2015 and ended December 2015 covering nine months for data collection from above mentioned settings.

Phase (I): Assessment phase:

Assessment the nurse's knowledge and performance through interviewing schedule for the nurses (pretest assessment). The pre-test was done to assess knowledge \& practices of the nurses regarding nursing care during the tocolytics agents administration in preterm labor. The data obtained during this phase constituted the baseline for further comparison to evaluate the effect of the educational program.

Each nurse was interviewed to collect data related to sociodemographic characteristics, assessed their baseline knowledge about preterm labor; tocolytics drugs. Each interview lasted 30-40 minutes. Data were collected from half of total nurses in the first shift. After collecting the assessments, data were collected from the other half of nurses from the other shift. This is followed by an observation of nurses' performance utilizing eleven checklists about nursing care during tocolytics administration to evaluate the nurse when she performs the physical assessment as deep tendon reflexes. Nurses should assess the signs of pulmonary edema, assess the daily weight, measure the intake and output, assess the uterine contraction, measure FHS by silicate, assess the vital signs, teach the mother breathing exercise and assess the time of bed rest and then record all findings in the woman's obstetric case worksheet. Each nurse was get a score according to the observational check list. If she passed $60 \%$ she is satisfied and if she hasn't passed $60 \%$, she is unsatisfied.

Phase (II): Planning phase:

The researchers developed the educational program, after comprehensive reviewing of the relevant literature, based on the obtained baseline data from assessment phase (pre-test). The Plan of nursing care is to manage preterm labor with tocolytics administration utilizing evidence-based practice depends on the needs of nurses as revealed from the scores of pretest assessment. The researchers developed a printed booklet in Arabic language to fulfil needs, cover knowledge and practices deficit and get the satisfaction of the participant nurses. It contained the definition of preterm labor, the risk factors, causes, signs and symptoms, diagnosis, complication, treatment, and the schedule of tocolytic drug which contained types, dose, route of administration, side effect, complication, and contraindication as well as nursing care during its administration.

The program had both general and specific objectives. The general one was to improve knowledge $\&$ practices of nurses regarding nursing care during tocolytics drugs administration for the cases of preterm labor. Moreover, the specific ones mentioned as each nurse, after completion of the program, should be able to:

- Define preterm labor.

- List causes of preterm labor.

- Identify complication of preterm labor on the mother.

- Identify complication of preterm labor on the fetus.

- Define tocolytics drug.

- Enumerate indication and uses of tocolytics drug.

- Enumerate contraindication of tocolytics drug.

- Describe side effect of tocolytics drug.

- Enumerate the most effective types of tocolytics drugs.

- Redemonstration of nursing care during tocolytics drugs administration by:

(1) Assess the deep tendon reflexes;

ISSN 2324-7940 E-ISSN 2324-7959 
(2) Assess the pulmonary edema;

(3) Assess the daily weight;

(4) Assess intake and output;

(5) Assess the uterine contraction;

(6) Assess the FHS;

(7) Measure temperature;

(8) Measure blood pressure;

(9) Measure the plus;

(10) Implement health teaching regarding breathing exercise;

(11) Assess the time of bed rest and continued observation therapeutic sleep for the women.

Phase (III): Implementation phase:

Implementation of the educational program took 12-week period (four weeks for each hospital). The researcher visited twice/week, alternatively. The educational program involved 2 scheduled sessions and were implemented according to nurses' working shift, load, and circumstances, nurses' time schedule, physical \& emotional readiness and permission from hospital director. These sessions were repeated to each subgroup of 2-6 nurses. The duration of each session took for 2 hours, including periods of discussion, using audiovisual presentation.

The first session aimed to increase the nurses' knowledge regarding preterm labor and tocolytic drugs. At the beginning of this session, an orientation to the educational program and its purpose took place, The Arabic language was used to suit the nurses' level of understanding. A presentation was held, it presented the definition of preterm labor, incidence, predisposing factors, signs and symptoms, complication, definition of tocolytics drug, uses, types, dose, rout and nursing care.

The second session aimed to improve the nurses' performance and technical skills toward nursing management during tocolytic drugs administration for women in preterm labor. It covered all procedures needed for woman's care, as mentioned above, and its importance followed by a demonstration. Repeat demonstrations occurred many times as participant nurses' needs.

Feedback was given in the beginning of each session about the previous one. Different methods of teaching were used such as modified lecture, group discussion, and brainstorming. Suitable teaching media were included an educational booklet that distributed to all nurses in the first day of the educational program as well as audio-visual aids.

Phase (IV): Evaluation phase:

Evaluation of the nurses was done, through post-test after one month (Post Test Assessment), to evaluate the effect of

Published by Sciedu Press the educational program. Monitoring outcome of nurses' knowledge and performance of the care for the patient on delaying the PTB.

\subsection{Administrative and ethical approval}

Official written letters were directed from the dean of the college of nursing in Port Said university the directorates of all public hospitals in Port Said city that included El-Tadamon general hospital, Port Said (El-Amery) general hospital, Port Fouad general hospital to obtain their permission to collect the research subject from Hospitals under their directorate. These letters described the aims and objectives of the study. After which time the study began.

In addition, the researcher took verbal consent from each nurse before including her in the study sample and after informed her about the aim and objectives of the study. Total confidentiality regarding obtained information as well as the respect for privacy was ensured. In addition, each nurse was informed that her participation in the study was totally voluntary, and that she could withdraw from the study whenever she decided.

\subsection{Statistical design}

After completion of data collection, it was categorized, scored, coded, arranged \& examined by utilizing personal computer (PC). Data entry was done using Epi-info computer software package, while statistical analysis was done using stat graphic, statistical software package, quality control was done at the stages of coding and data entry. Statistical analysis was done using SPSS 11.0 (Statistical Package for the Social Science) software packages. The next mentioned statistical tests were used:

- Descriptive statistics as frequencies, range, percentage, mathematical mean and standard deviation (Mean $\pm S D$ ).

- Statistical tests included: Chi-square $\left(\chi^{2}\right)$ test, Paired sample $T$-test, and Kruskal-Wallis test.

- The graphical presentation included Pie and Column chart diagram.

- All analysis and observed differences were considered statistically significant at the 5\% level $(p \leq .05)$.

\section{Results}

Table 1 shows the distribution of study subject according to their age and years of experience in their job. Regarding age, the half of the participant nurses $(50 \%)$ were in the age group ranging between 20 years to less than 30 years, while those aged 50 years or more constituted $6.6 \%$ of the subjects. Regarding the experience in nursing jobs, the mean years 
of experience in nursing in the present study were around $10.8 \pm 9.3$.

Figure 1 illustrates the distribution of the participant nurses regarding to their educational level and job characteristics (place of work) data. It presents that $36.7 \%$ of the studied nurses worked at El-Amery hospital. Eighty-six point six percent had a nursing secondary school education.

Table 1. Distribution of the study subject according to their age and duration of experiences $(n=30)$

\begin{tabular}{|c|c|c|}
\hline Socio-demographic characteristics & No. & $\%$ \\
\hline \multicolumn{3}{|l|}{ Age (years) } \\
\hline - Less than 20 & 3 & 10.0 \\
\hline - 20 - & 15 & 50.0 \\
\hline - 30 - & 5 & 16.7 \\
\hline - 40 - & 5 & 16.7 \\
\hline - More than 50 & 2 & 6.6 \\
\hline Range & $18-55$ & \\
\hline Mean \pm SD & $30.6 \pm 10.3$ & \\
\hline \multicolumn{3}{|l|}{ Duration of experience } \\
\hline - Less than 10 years & 17 & 56.6 \\
\hline$\cdot \geq 10$ years & 5 & 16.7 \\
\hline - $\geq 20$ years & 6 & 20.0 \\
\hline - $\geq 30$ years & 2 & 6.7 \\
\hline Range & $1-31$ & \\
\hline Mean \pm SD & $10.8 \pm 9.3$ & \\
\hline
\end{tabular}

Table 2 presents the nurses' knowledge about preterm labor before and after the intervention of guidelines. It indicated that about two-thirds of them did not know the correct definition of the preterm labor, in while $73.3 \%$ of them stated the definition correctly in post-test and, these differences were statistically significant. Regarding mother complications, the most stated complications in pre $\&$ post program were maternal death; $16.7 \%$ of the sample were recorded sepsis pre-test compared with $20 \%$ in post-test, $10.0 \%$ were recorded the postpartum hemorrhage compared with 50\% in post-test, these differences was statistically significant. Additionally, in relation to fetal complications, a statistical difference was found between pre and post-test $(p<.01)$. Forty-six point seven percent recorded that the complication was an intra-amniotic infection in pre-test compared with $56.7 \%$ in post-test.

Knowledge about tocolytics drug is presented in Table $3 \&$ Figure 2. This part assesses the nurses' knowledge about tocolytics drugs, which included the definition, types, contraindication, uses, side effect and nursing care as well as the most effective types of tocolytics drugs. Additionally, the total score of nurses' knowledge is presented in Table 4.

Table 3 revealed that there was an improvement of the nurse's knowledge in all items (definition, indication, contraindication and side effect) regarding the knowledge of tocolytics drugs. These improvements were statistically significant. The most prominent improvement was in the knowledge about the side effect of tocolytics which reached from $26.7 \%$ in pre-test to $100 \%$ immediately after the post-test; statistically significant $(p<.01)$.

Figure 2 summarizes nurse's knowledge about the most common types of tocolytics. This figure showed that, paired $T$-test indicated statistical significant difference between pre and post-test, $T=5.435$ which indicates that nurses gained knowledge about types of tocolytics; $13.3 \%$ of the nurses recorded Ritodrine in pre-test compared with $16.7 \%$ in posttest, $30 \%$ in pre-test was record magnesium sulfate compared with $50 \%$ in post-test; $16.7 \%$ was record Nifedipine compared with $40.0 \%$ and $13.3 \%$ in pre-test compared $23.3 \%$ was record Atosiban in post-test $(p<.001)$.
Figure 1. Distribution of the participant nurses according to their educational level and job place of work

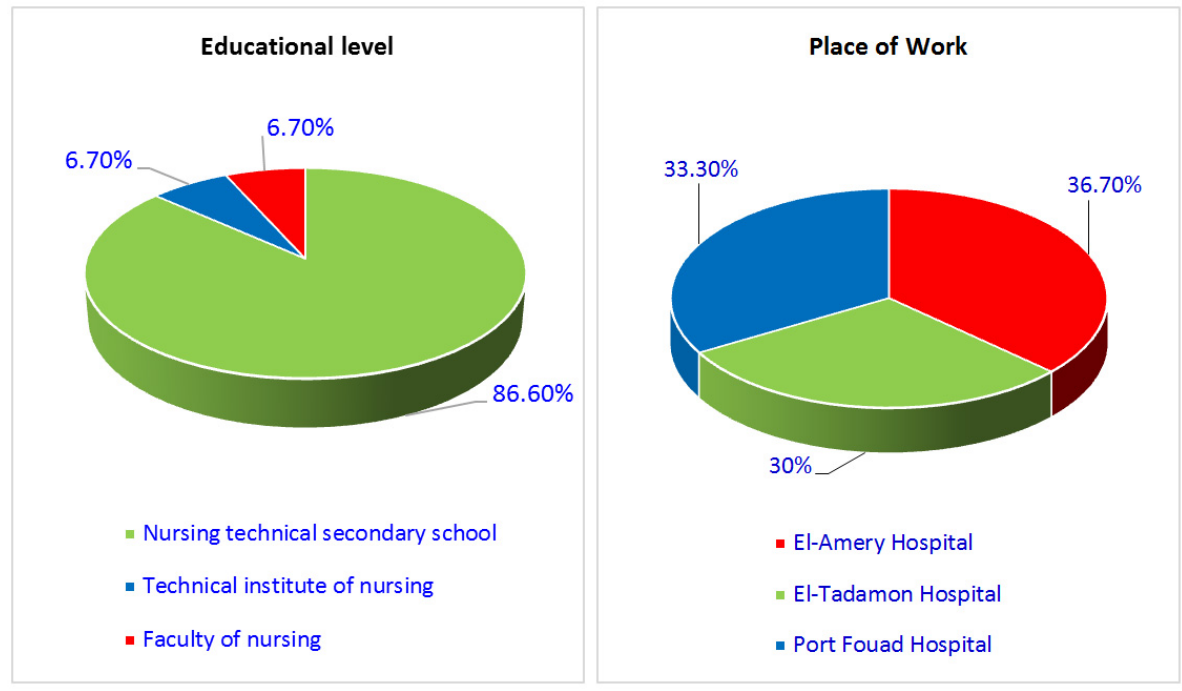


Table 2. Comparison of pre \& post scores of nurses' knowledge about preterm labor

\begin{tabular}{|c|c|c|c|c|c|c|}
\hline \multirow{2}{*}{ Item } & \multicolumn{2}{|c|}{ Pre-test } & \multicolumn{2}{|c|}{ Post-test } & \multirow{2}{*}{$\chi^{2}$} & \multirow{2}{*}{$p$} \\
\hline & $\mathbf{N}$ & $\%$ & $\mathbf{N}$ & $\%$ & & \\
\hline \multicolumn{7}{|l|}{ Definitions of preterm Labor } \\
\hline - Correct & 10 & 33.3 & 22 & 73.3 & \multirow{2}{*}{18.58} & \multirow{2}{*}{$<.01^{* *}$} \\
\hline - Incorrect & 20 & 66.7 & 8 & 26.7 & & \\
\hline \multicolumn{7}{|l|}{ Causes of Preterm Labor \# } \\
\hline - Infection & 0.0 & 0 & 2 & 6.7 & \multirow{6}{*}{23.40} & \multirow{6}{*}{$<.01^{* *}$} \\
\hline - Hypertension & 8 & 26.7 & 12 & 40 & & \\
\hline - Uterine malformation & 3 & 10.0 & 10 & 33.3 & & \\
\hline - Life style & 7 & 23.3 & 10 & 33.3 & & \\
\hline - Diabetes Mellitus (DM) & 0.0 & 0 & 4 & 13.3 & & \\
\hline - Polyhydramnios & 1 & 3.3 & 8 & 26.7 & & \\
\hline \multicolumn{7}{|l|}{ Complication on mother ${ }^{\#}$} \\
\hline - Sepsis & 5 & 16.7 & 6 & 20 & \multirow{3}{*}{20.04} & \multirow{3}{*}{$<.01^{* *}$} \\
\hline - Postpartum hemorrhage (PPH) & 3 & 10.0 & 15 & 50.0 & & \\
\hline - Maternal death & 21 & 70.0 & 18 & 60.0 & & \\
\hline \multicolumn{7}{|l|}{ Complication on fetus ${ }^{\#}$} \\
\hline - Respiratory distress syndrome (RDS) & 3 & 10.0 & 7 & 23.3 & \multirow{4}{*}{17.33} & \multirow{4}{*}{$<.01^{* *}$} \\
\hline - Intra amniotic infection & 14 & 46.7 & 17 & 56.7 & & \\
\hline - Immature heart & 11 & 36.7 & 10 & 33.3 & & \\
\hline - Immature lung & 2 & 6.7 & 3 & 10.0 & & \\
\hline
\end{tabular}

${ }^{\#}$ more than one answer; ${ }^{* *}$ moderate significant difference

Table 3. Pre \& post scores nurses' knowledge about tocolytics drug

\begin{tabular}{|c|c|c|c|c|c|c|c|c|c|c|}
\hline \multirow{3}{*}{ Item } & \multicolumn{4}{|c|}{ Pretest Group } & \multicolumn{4}{|c|}{ Post-test Group } & \multirow{3}{*}{$\chi^{2}$} & \multirow{3}{*}{$p$} \\
\hline & \multicolumn{2}{|c|}{ Correct } & \multicolumn{2}{|c|}{ Incorrect } & \multicolumn{2}{|c|}{ Correct } & \multicolumn{2}{|c|}{ Incorrect } & & \\
\hline & $\mathbf{N}$ & $\%$ & $\mathbf{N}$ & $\%$ & $\mathbf{N}$ & $\%$ & $\mathbf{N}$ & $\%$ & & \\
\hline Definition of Tocolytics drug & 10 & 33.3 & 20 & 66.7 & 21 & 70.0 & 9 & 30.0 & 18.581 & $<.01^{* * n}$ \\
\hline Contraindication of Tocolytics drug & 11 & 36.7 & 19 & 63.3 & 21 & 70.0 & 9 & 30.0 & 0.307 & $<.01^{* *}$ \\
\hline Uses (indications) of Tocolytics drug & 7 & 23.3 & 23 & 67.7 & 22 & 73.3 & 8 & 26.7 & 17.926 & $<.01^{* * *}$ \\
\hline Side effect of Tocolytics drug & 8 & 26.7 & 22 & 73.3 & 30 & 100 & 00 & 00 & 30.031 & $<.01^{* * *}$ \\
\hline
\end{tabular}

moderate significant difference

Table 4 presents the total score of nurses' knowledge regarding preterm labor and tocolytics. This table showed that; paired $T$-test indicated a statistically significant difference between total scores of knowledge in pre and post-test, the mean scoring $(4.79 \pm 1.735)$ in pre-test compared with $(18.08 \pm 1.911)$ in post-test $(p<.001, t=49.23)$.

Nursing care during the tocolytics drugs administration for women in preterm labor, as recorded in the observation checklist, is revealed in Table 5. Chi-square revealed statistically significant differences between pre and post-test $\left(\chi^{2}=17.633, p<.01\right)$. In relation to performance scoring between pre and post-test, the points evaluated in 11 points. This table showed that there was statistically significant difference in the improvement of skills between pre and post-test. Twenty percent of the nurse's performances were satisfactory in pre-test become $86.7 \%$ in the post-test.

The relationship between nurses' job characteristics and their scoring of knowledge and performance is illustrated in Table 6. Although, all nurses archived better scoring in both knowledge and skills after implementing the program than before it (progression of satisfactory score and regression of unsatisfactory one), regarding all aspects of the nurses' job characteristics, no statistically significant differences observed in neither nurses' performance $(p=.622 \& p=.358)$ nor nurses' knowledge $(p=.965 \& p=.835)$ regarding years of experience and Place of work, respectively, at the level of $(p<.05)$. Additionally, the same table revealed that, there is no statistically differences between nurses' performance score $(T=1.054 \& p=.568)$ as well as nurses' knowledge score $(T=.685 \& p=.755)$ and their level of education. 
Figure 2. Nurse's knowledge about the most effective types of tocolytics drugs *** highly significant difference

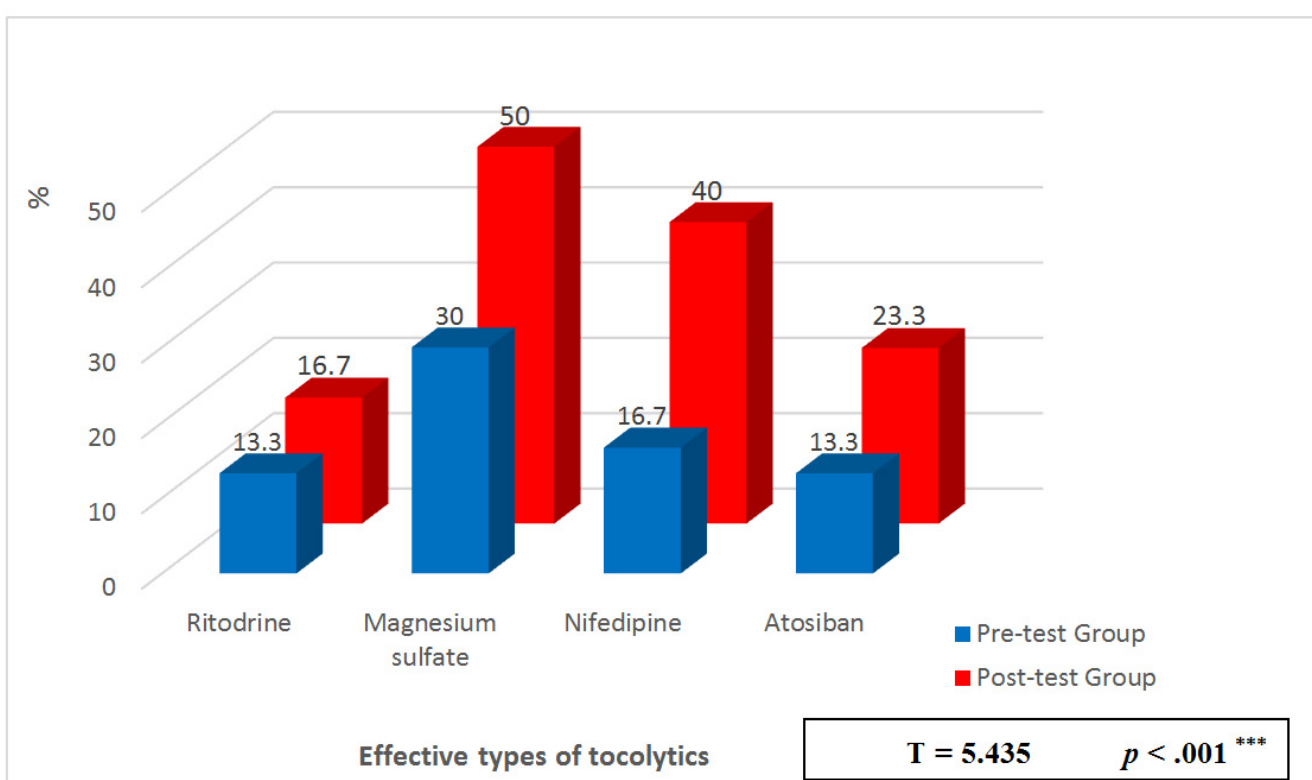

Table 4. Comparison pre \& post-test scores regarding the nurse's knowledge

\begin{tabular}{|c|c|c|c|c|c|c|}
\hline \multirow{2}{*}{ Item } & \multicolumn{2}{|c|}{ Pre-test } & \multicolumn{2}{|c|}{ Post-test } & \multirow{2}{*}{$T$} & \multirow{2}{*}{$p$} \\
\hline & $\chi^{2}$ & $S D$ & $\chi^{2}$ & $S D$ & & \\
\hline Knowledge scoring & 4.79 & 1.735 & 18.08 & 1.911 & 49.23 & $<.001^{* *}$ \\
\hline
\end{tabular}

${ }^{* * * *}$ highly significant difference

Table 5. Comparison pre \& post-test scores of nurses' performance about nursing care during the use of tocolytics drugs of preterm labor

\begin{tabular}{|c|c|c|c|c|c|c|c|c|c|c|}
\hline \multirow{3}{*}{ Item } & \multicolumn{4}{|c|}{ Pre-test Group } & \multicolumn{4}{|c|}{ Post-test Group } & \multirow{3}{*}{$\chi^{2}$} & \multirow{3}{*}{$p$} \\
\hline & \multicolumn{2}{|c|}{ Done } & \multicolumn{2}{|c|}{ Not done } & \multicolumn{2}{|c|}{ Done } & \multicolumn{2}{|c|}{ Not done } & & \\
\hline & $\mathbf{N}$ & $\%$ & $\mathbf{N}$ & $\%$ & $\mathbf{N}$ & $\%$ & $\mathbf{N}$ & $\%$ & & \\
\hline 1. Assess the Deep Tendon Reflexes & 8 & 26.7 & 22 & 73.3 & 24 & 80 & 6 & 20 & 1.067 & $<.01^{* * *}$ \\
\hline 2. Assess the Pulmonary Edema & 12 & 40 & 18 & 60 & 23 & 76.7 & 7 & 23.3 & 1.389 & $<.01^{* *}$ \\
\hline 3. Assess the daily weight & 16 & 53.3 & 14 & 46.7 & 22 & 73.3 & 8 & 26.7 & 2.622 & .086 \\
\hline 4. Assess Intake and Output & 16 & 53.3 & 14 & 46.7 & 17 & 56.7 & 13 & 43.3 & 0.036 & .581 \\
\hline 5. Assess the Uterine Contraction & 14 & 46.7 & 16 & 53.3 & 25 & 83.3 & 5 & 16.7 & 8.450 & $.003^{* *}$ \\
\hline 6. Assess the fetal heart sound & 12 & 40 & 18 & 60 & 26 & 86.7 & 4 & 13.3 & 12.000 & $<.001^{* * *}$ \\
\hline 7. Measure temperature & 23 & 76.7 & 7 & 23.3 & 26 & 86.7 & 4 & 13.3 & 0.364 & .549 \\
\hline 8. Measure blood pressure & 9 & 30.0 & 21 & 70.0 & 26 & 86.7 & 4 & 13.3 & 13.793 & $<.001^{* * *}$ \\
\hline 9. Measure plus & 6 & 20 & 24 & 80 & 28 & 93.3 & 2 & 6.7 & 17.875 & $<.01^{* *}$ \\
\hline 10. Health teaching regarding breathing exercise & 12 & 40 & 18 & 60 & 23 & 76.7 & 7 & 23.3 & 1.389 & $<.01^{* *}$ \\
\hline 11. Assess the time of bed rest & 14 & 46.7 & 16 & 53.3 & 29 & 96.7 & 1 & 3.3 & 18.050 & $<.001^{* * *}$ \\
\hline \multicolumn{11}{|l|}{ Total performance scoring } \\
\hline - Satisfactory $>60 \%$ & 6 & & 20 & & 26 & & 86.7 & & 33 & \\
\hline - Unsatisfactory $<60 \%$ & 24 & & 80 & & 4 & & 13.3 & & 033 & 2.01 \\
\hline
\end{tabular}

${ }^{* *}$ moderate significant difference; ${ }^{* * *}$ highly significant difference

\section{Discussion}

World Health Organization (WHO) defines the PTB as any baby born fewer than 259 days or before thirty-seven completed weeks of gestation since the 1st day of the women's last menstrual period (LMP). ${ }^{[2]}$ However, The American College of Obstetricians \& Gynecologists has proposed the criteria to document preterm labor between $20^{t h} \& 37^{\text {th }}$ weeks' gestation as the following: uterine contractions occurring at a frequency of 4 in 20 minutes or 8 in 60 minutes plus progressive cervical changes, cervical dilatation greater than $1 \mathrm{~cm}$, cervical effacement of $80 \%$ or greater. ${ }^{[21]}$ As preventive strategies are largely ineffective, vulnerable preterm 
labor could be a frequent problem that affects about $10 \%$ of pregnancies. ${ }^{[2]}$ For many women in preterm labor it may not be appropriate to consider tocolysis, wherever it is appropriate $\&$ safe to do so, tocolysis administration aims to delay PTB to allow time for in-utero transfer to a tertiary perinatal center for multidisciplinary intervention and management, and/or maternal administration of corticosteroids to enhance and accelerate fetal surfactant production and lung maturation so this might reduce neonatal mortality and severe morbidity with no long-term side effects. ${ }^{[22]}$

Table 6. Relationship between nurses' job characteristics and their scoring of knowledge and performance

\begin{tabular}{|c|c|c|c|c|c|c|c|c|c|c|}
\hline \multirow{4}{*}{ Item } & \multicolumn{8}{|c|}{ Performance scoring } & \multirow{3}{*}{\multicolumn{2}{|c|}{$\begin{array}{c}\text { Knowledge scoring } \\
\text { Post-test }\end{array}$}} \\
\hline & \multicolumn{4}{|c|}{ Satisfactory } & \multicolumn{4}{|c|}{ Unsatisfactory } & & \\
\hline & \multicolumn{2}{|c|}{ Pre-test } & \multicolumn{2}{|c|}{ Post-test } & \multicolumn{2}{|c|}{ Pre-test } & \multicolumn{2}{|c|}{ Post-test } & & \\
\hline & $\mathbf{N}$ & $\%$ & $\mathbf{N}$ & $\%$ & $\mathbf{N}$ & $\%$ & $\mathbf{N}$ & $\%$ & $\chi^{2}$ & $S D$ \\
\hline \multicolumn{11}{|l|}{ Experience years } \\
\hline$\bullet<10$ Years & 4 & 23.5 & 15 & 88.2 & 13 & 76.5 & 2 & 11.8 & 18.13 & 1.821 \\
\hline \multirow[t]{2}{*}{$\cdot \geq 10$ Years } & 6 & 46.2 & 9 & 69.2 & 7 & 53.8 & 4 & 30.8 & 18.04 & 2.011 \\
\hline & \multicolumn{4}{|c|}{$\mathrm{T}=0.243$} & \multicolumn{4}{|c|}{$p=.622$} & $\mathrm{~T}=0.457$ & $p=.965$ \\
\hline \multicolumn{11}{|l|}{ Place of work } \\
\hline - El-Amery & 4 & 36.4 & 8 & 72.7 & 7 & 63.6 & 3 & 27.3 & 18.20 & 1.814 \\
\hline - El-Tadamon & 1 & 11.1 & 9 & 100 & 8 & 88.9 & 0 & 0 & 18.33 & 1.936 \\
\hline \multirow[t]{2}{*}{ - Port Fouad } & 4 & 40 & 6 & 60 & 6 & 60 & 4 & 40 & 17.90 & 2.024 \\
\hline & \multicolumn{4}{|c|}{$\mathrm{T}=2.054$} & \multicolumn{4}{|c|}{$p=.358$} & \multicolumn{2}{|c|}{$\begin{array}{l}(\text { Kruskal-Wallis })=0.362 \\
p=.835\end{array}$} \\
\hline \multicolumn{11}{|l|}{ Educational level } \\
\hline $\begin{array}{c}\text { - Nursing technical } \\
\text { secondary school }\end{array}$ & 6 & 23.1 & 22 & 84.6 & 20 & 76.9 & 4 & 15.4 & 18.30 & 1.895 \\
\hline $\begin{array}{l}\text { - Technical institute of } \\
\text { nursing }\end{array}$ & 0 & 0.0 & 2 & 100 & 2 & 100 & 0 & 0.0 & 18.33 & 1.945 \\
\hline \multirow[t]{2}{*}{ - Faculty of nursing } & 1 & 50.0 & 2 & 100 & 1 & 50.0 & 0 & 0.0 & 17.90 & 2.011 \\
\hline & \multicolumn{4}{|c|}{$\mathrm{T}=1.054$} & \multicolumn{4}{|c|}{$p=.568$} & $\mathrm{~T}=0.685$ & $p=.755$ \\
\hline
\end{tabular}

As the nursing care is the main critical component of therapy for those women who experience preterm labor, Nurses' Knowledge deficit and poor practical skills regarding tocolytics administration and care surely will interfere with their ability to achieve consistent and positive patient care outcomes. ${ }^{[23]}$ So nurses should have the basic necessary knowledge and technical skills to offer the care safely, be trained accurately in practical and technical procedures to be able to use this knowledge effectively. ${ }^{[24]}$ Nursing personnel should play an important role in this area as educators as well as health promoters of patients. Additionally, they should also collaborate with other different health professionals to determine the effectiveness of therapy and, therefore, the causes of preterm labor. If prematurity has gained national attention with public \& professional awareness, perhaps this problem will decrease. ${ }^{[25]}$ In this respect, this study was carried out to evaluate the impact of an educational program on nurses' knowledge and nursing management of preterm labor women receiving tocolytics. The findings are discussed in two areas related to these core elements; nurses' knowledge and nurses' performance.

The results of the present study regarding the nurses' knowledge of preterm labor; the pre-test of the present study re- vealed that the majority of the nurses hadn't the correct knowledge about definition, causes, complications neither for the mother nor for the fetus. This lack of knowledge may be attributed to the lack of or defective curriculum as the majority $(86.6 \%)$ of the participant nurses had a technical secondary level of nursing education. After attending the guidelines, the results indicated that there is a significant increase in the nurses' knowledge. This improvement was also maintained up to the follow-up test through the observed care of women during collected the sample size of nurses. This improvement could be attributed to the attendance at sessions of guidelines and the lecture and positive reinforcement or the long-term retention of knowledge. In this respect, Masters K. ${ }^{[26]}$ and Yeh et al. ${ }^{[27]}$ mentioned that it is widely cited that people remember $10 \%$ of what they hear, $20 \%$ of what they read.

Furthermore, nurses' knowledge about tocolytics drugs; the results of this study have indicated that nurses' knowledge before the guidelines were under the required standard. The majority of the nurses were unfamiliar with the definition of tocolytics, indications, types, side effect and contraindications. This lack of knowledge may be attributed to the lake of, or defective of the basic nursing education, after attending 
the program. The result indicated that there is a significant increase in the nurses' knowledge. This improvement was also maintained up to the post-test assessment. This improvement could be attributed to the attendance at sessions of the program and the lecture and positive reinforcement.

In brief, the total score of nurses' retained knowledge regarding preterm labor and tocolytics was significantly improved from $(4.79 \pm 1.735)$ in pre-test to $(18.08 \pm 1.911)$ in posttest. This improvement could be attributed to the varieties of educational methods which used by the researcher as lectures, audiovisual materials and discussion as well as Arabic booklet which distributed to every nurse. In many educational programs, too much dependence is placed on distributing written materials in the form of booklets. They can remind the nurses of the topics they have already learned in other ways. They can provide additional information about any health practice for those who have a special interest in it. Booklets are best used when they are brief, written in plain language, full of good pictures and when they are used to back-up other forms of education. This is in accordance with Edgar Dale's or the NTL's Pyramid of Learning as cited by Masters K. ${ }^{[26]}$ as the pyramid illustrated that individuals can retain $10 \%$ of what he read and $20 \%$ of what he sees and hear (audiovisual). The same author added that, ones can retain $50 \%$ of what he learned by discussion (see Figure 3).
Figure 3. Edgar Dale's or the NTL's Pyramid of Learning ${ }^{[28]}$

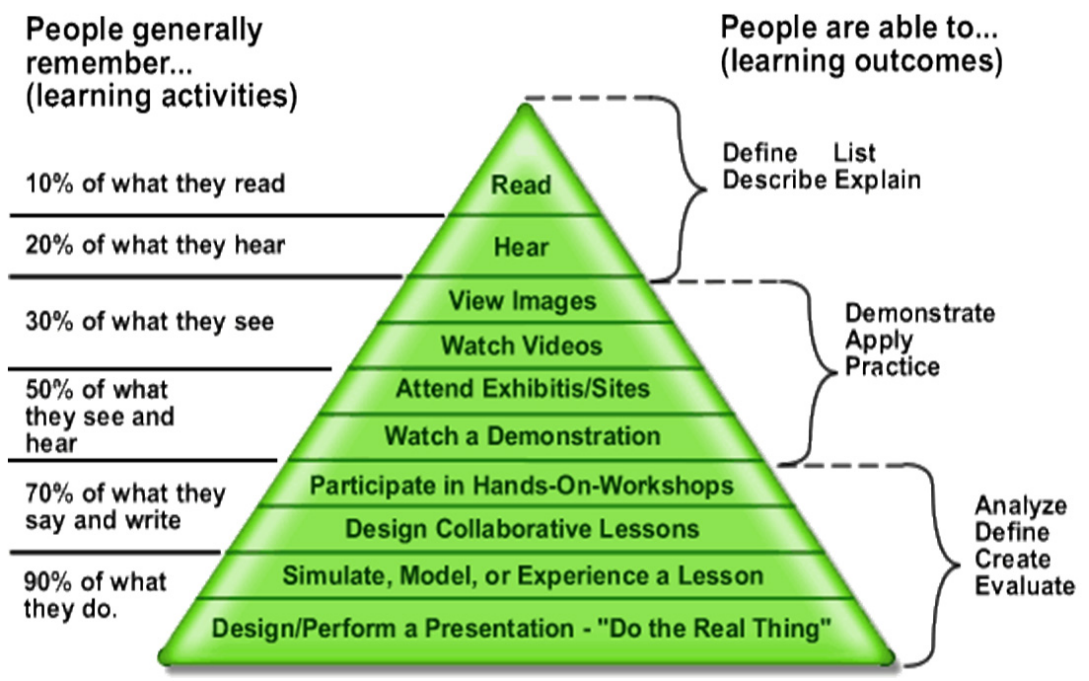

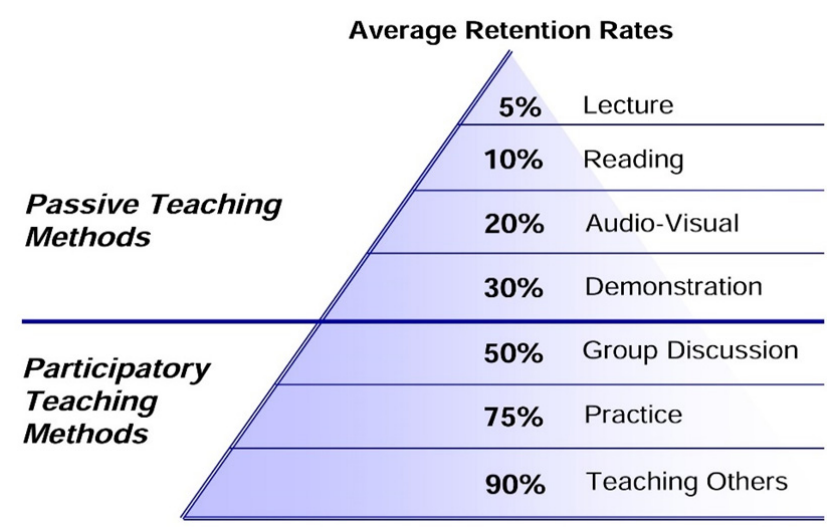

Figure 4. The Learning Pyramid ${ }^{[29]}$

Adapted from National Training Laboratories. Bethel, Maine

In the present study, nurses' performance of the skills was an important factor in producing real change in nurses practice regarding deep tendon reflex, assess the pulmonary edema, uterine contraction, FHS, intake \& output, daily weight, vital signs, health education of breathing exercise and assessment the time of bed rest as well as continued observation therapeutic sleep for the women. It is noticed that the pre-test showed unsatisfactory performance and after implementation of the guidelines, all nurses in post-test performed skills satisfactorily. This result is in agreement with Edgar Dale's or the NTL's Pyramid of Learning (see Figure 3) and/or articles that deal with medical education which examines the percentages of learning retention associated with the Pyramid. They describe the retention rates of knowledge. After two weeks a person tends to remember $30 \%$ of what he sees, $50 \%$ of what he sees and hear as watch live demonstration. These percentages of retention will increase to $70 \%$ of what we personally experience. ${ }^{[26-28]}$ In the same line, the National Training Laboratories Institute (see Figure 4) has found that ones can retain $30 \%$ of what he learned by demonstration and $75 \%$ by Practice by doing. ${ }^{[29]}$

Therefore, the present program succeeded in giving nurses the required skills. The total performance scoring improved from $20 \%$ to percentage $86.7 \%$. This is expected as various authors commented about the importance of training programs in promoting technical skills. ${ }^{[30]}$ This result is in 
agreement with The Association of Women's Health, ${ }^{[31]}$ who found that $80 \%$ or more to qualify for certificate nursing education (CNE) must be completed in order to access CNE certificates which can be printed by the participants upon their successful completion of the online learning program. There is the opportunity to learn up to 64.3 contact hours with this program.

The relationship between knowledge of the participant nurses, related to preterm labor and tocolytics drugs, and their experiences \& place of work were investigated in this study. The results revealed that neither the years of experience nor the place of works had an influence on their knowledge about preterm labor and tocolytics drugs. Concerning nurses' skills towards the nursing care of preterm labor and the care of tocolytics, it was found that the place of work and years of experiences didn't have any influence on these skills. This result is not in agreement with the studies carried out by The Association of Women's Health, ${ }^{[31]}$ which have demonstrated that the years of experiences was associated with more positive. The findings were not in line with the fact that dayby-day life enhances the nurse's experiences and improve their knowledge. Additionally, although, there are no statistical differences between nurses' knowledge and performance score regarding their level of education, it was observed that generally nurses who have higher educational having higher score of both knowledge and practical score than lower ones. Moreover, the impact of an educational program on the nursing performance was positive for all of them and progress their knowledge and practices. These findings are supported by Sabilu Y. et al. ${ }^{[32]}$ who reported, the level of education affects the learning process, the higher the person's level of education the easier person to receive information. However, it should be emphasized that a low education does not mean absolute knowledge also lower. Increased knowledge is not absolute acquired in formal education. There are several factors that influence a person's knowledge, among others,

\section{REFERENCES}

[1] World Health Organization (WHO). Preterm birth: Fact sheet. Media centre. 2016.

[2] Hermans F, Schuit E, Pmeer B, et al. Effectiveness of a cervical pessary for women who did not deliver $48 \mathrm{~h}$ after threatened preterm labor (Assessment of perinatal outcome after specific treatment in early labor: Apostel VI trial). BMC Pregnancy and Childbirth. 2016; 16-154. https://doi.org/10.1186/s12884-016-0935-7

[3] American College of Obstetricians and Gynecologists (ACOG): practice bulletin. Management of preterm labor (number 43). Int J Gynecology Obstet. 2003; 82(1): 127-35. PMid: 12834934. intelligence, experience, information, health education given through the media information.

\section{Conclusions}

Based on the results of the present study, it is presumed that the hypothesis of the study is accepted. All nurses archived better scoring in both knowledge and skills after implementing the program than before it. There is a progression in satisfactory score and regression in unsatisfactory one. This is mirrored the effect of the program.

\subsection{Recommendations}

In the light of the findings of this study, the following is recommended.

(1) Continuing educational programs should be developed to teach and train nurses about the care of preterm, a complete assessment of maternal history, accurate examination of preterm labor and knowledge of tocolytics drugs.

(2) Every hospital should update the guidelines during the treatment of preterm labor with women who received tocolytics drugs.

(3) The intervention guidelines nursing care of tocolytics drugs are strongly recommended as a way to reduce the incidence of complications of preterm labor.

\subsection{Limitation of the study}

In some cases, the sessions were extended because of subject's workload, noise and other people's interference and interruption which added extra time and more effort. Furthermore, a deficient number of studies that focus on nurses' role, knowledge and practices regarding the care of pregnant women with tocolytics administration for inhibiting preterm labor.

\section{Conflicts of Interest Disclosure}

The authors declare they have no conflicts of interest.
[4] March of Dimes, Partnership for Maternal NaCH, Save the Children, World Health Organization. Born too soon: The global action report on preterm birth. Geneva: World Health Organization; 2012.

[5] EURO-PERISTAT Project. European Perinatal Health Report. The Health and Care of Pregnant Women and Babies in Europe in 2010. 2013.

[6] Li Z, Zeki R, Hilder L, et al. Australia's mothers and babies 2011. Perinatal statistics series no. 28. Cat. no. PER 59. Canberra. Australian Institute of Health and Welfare, National Perinatal Epidemiology and Statistics Unit. 2013.

[7] Queensland Government. Perinatal statistics 2011 annual report. 
Health Statistics Unit. 2011 [cited 2014, May 13]. Available from: http://www .health.qld.gov.au/hsu/peri/peri2011

[8] Clinical Practice Guideline: Tocolytic Treatment in Pregnancy. Institute of Obstetricians and Gynecologists, Royal College of Physicians of Ireland and Directorate of Strategy and Clinical Care Health Service Executive. 2015; 1-21.

[9] Durnwald CP, Walker H, Lundy JC, et al. Rates of recurrent preterm birth by obstetrical history and cervical length. Am J Obstet Gynecol. 2005; 193(3 Pt 2): 1170-4. PMid: 16157132. https://doi.org/ $10.1016 / j$. ajog. 2005.06.085

[10] Blencowe H, Cousens S, Oestergaard MZ, et al. National, regional, and worldwide estimates of preterm birth rates in the year 2010 with time trends since 1990 for selected countries: a systematic analysis and implications. Lancet. 2012; 379(9): 2162-2172. https : //doi.org/10.1016/S0140-6736(12)60820-4

[11] Goldenberg RL, Rouse DJ. The prevention of premature birth. N Engl J Med. 1998; 339: 313-20. PMid: 9682045. https ://doi .or $\mathrm{g} / 10.1056 /$ NEJM199807303390506

[12] Eden A. Prevention of preterm birth in high-risk patients: the role of education, Acta Obstet Gynecol Scand. 2005; 84: 526-533.

[13] Gaunekar N, Raman P, Bain E, et al. Maintenance therapy with calcium channel blockers for preventing preterm birth after threatened preterm labour. Cochrane Database of Systematic Reviews. 2013; 10. https://doi.org/10.1002/14651858.CD004071.pub3

[14] Queensland Clinical Guidelines Maternity and neonatal clinical guideline: Preterm labour and birth. Queensland government. 2016: $1-26$.

[15] Preterm labor management. United Health care: Oxford Clinical Policy. 2016: 1-8.

[16] Iams JD, Goldenberg RL, Meis PJ. The length of the cervix and the risk of spontaneous premature delivery. National Institute of Child Health and Human Development Maternal Fetal Medicine Unit Network. N Engl J Med. 2002; 334: 567-572. PMid: 8569824. https://doi .org/10.1056/NEJM199602293340904

[17] Sullivan CA, Morrison JC. Emergent management of the patient in preterm labor. Obstet Gynecol Clin North Am. 1999; 22: 197-214.

[18] England M. Review of Psychotherapy for the advanced practice psychiatric nurse. Perspectives in Psychiatric Care. 2008; 44(3): 219-220. https://doi.org/10.1111/j.1744-6163.2008.00179.x

[19] Webster S, Gallagher S, Brown P, et al. The perceptions of nurses in their management of patients experiencing anxiety. Journal of Nursing Education and Practice. 2012; 2(3): 38-45.

[20] Hassan H. Infertility profile, psychological ramifications and reproductive tract infection among infertile women, in northern Upper Egypt. Journal of Nursing Education and Practice. 2016; 6(4): 92108. https://doi.org/10.5430/jnep.v6n4p92
[21] Chalermchockcharoenkit A. Preterm Labor. Thai Journal of Obstetrics and Gynaecology. 2002; 14: 85-98.

[22] Abdulkareem N, Abbas I. Knowledge of mothers with premature births About Antenatal Corticosteroid Therapy for fetal lung maturation. IOSR Journal of Nursing and Health Science. 2016; 5(6): 80-86.

[23] Jones D, Collins B. The nursing management of women experiencing preterm labor: clinical guidelines and why they are needed. Journal of obstetric, genecology \& neonatal nursing (JOGNN). The Association of Women's Health, Obstetric and Neonatal Nurses (AWHONN). 1996; 25(7): 569-592. https://doi.org/10.1111/j.1552-690 9.1996.tb02117.x

[24] Gomez R, Romero R, Medina L. Cervicovaginal fibronectin improves the prediction of preterm delivery based on sonographic cervical length in patients with preterm uterine contractions and intact membranes. Am J Obstet Gynecol. 2005; 192: 350-359. PMid: 15695971. https://doi.org/10.1016/j.ajog. 2004.09.034

[25] Nasr E, Hassan H. Association between quality of family planning services and client's satisfaction level in maternal and child health centers in Port Said city. Journal of Nursing Education and Practice. 2016; 6(1): 85-99.

[26] Masters K. Edgar Dale's Pyramid of Learning in medical education: A literature review, Medical Teacher. 2013; 35(11): e1584-e1593. https://doi.org/10.3109/0142159X.2013.800636

[27] Yeh MK, Hsieh HC, Chang SH, et al. Problem-based learning achievement of K-12 students participating in a nanotechnology handson works exhibition in Taiwan. Int J Cross-Discip Subjects Educ. 2011; 2(3): 480-486. https://doi.org/10.20533/ijcdse.20 42.6364 .2011 .0066

[28] Thalheimer W. Debunk This: People Remember 10 Percent of What They Read. Thursday, March 12, 2015.

[29] Kumar A. Personal, Academic and Career Development in Higher Education - SOA Ring to Success London and New York: Routledge Taylor \& Francis Group; 2007.

[30] McPheeters ML, Miller WC, Hartmann KE. The epidemiology of threatened preterm labor: a prospective cohort study. Am J Obstet Gynecol. 2005; 192: 1325-1329. PMid: 15846230. https : //doi.org/10.1016/j.ajog.2004.12.055

[31] Association of Women's Health: Obstetric and Neonatal Nurses is accredited as a provider of continuing nursing education by the American Nurses Credentialing Center's Commission on Accreditation. 2008.

[32] Sabilu Y, Kusnan A, Saptaputra S, et al. The Sexually Transmitted Infection (STI) In Women Sexual Workers (WSW) in Southeast Sulawesi Province. IOSR Journal of Nursing and Health Science. 2016; 5(6): 119-122. https://doi:10.9790/1959-050601119122 